TITLE:

\title{
Greenwoodochromini Takahashi from Lake Tanganyika is a junior synonym of Limnochromini poll (Perciformes: Cichlidae).
}

\author{
AUTHOR(S): \\ Takahashi, T
}

\section{CITATION:}

Takahashi, T. Greenwoodochromini Takahashi from Lake Tanganyika is a junior synonym of Limnochromini poll (Perciformes: Cichlidae).. Journal of fish biology 2014, 84(4): 929936

\section{ISSUE DATE:}

2014-02-12

URL:

http://hdl.handle.net/2433/198633

\section{RIGHT:}

This is the peer reviewed version of the following article: Takahashi, T. (2014), Greenwoodochromini Takahashi from Lake Tanganyika is a junior synonym of Limnochromini Poll (Perciformes: Cichlidae). Journal of Fish Biology, 84:

929-936, which has been published in final form at http://dx.doi.org/10.1007/s10228-014-0396-9.; この論文は出版社版 でありません。引用の際には出版社版をご確認ご利用ください。; This is not the published version. Please cite only the published version. 
Laboratory of Animal Ecology, Graduate School of Science, Kyoto University, 
25 The infraorbitals (IOs) of four species endemic to Lake Tanganyika were examined.

26 Based on the examination of the IOs and previous morphological and molecular studies,

27 the tribe Greenwoodochromini is synonymised with the tribe Limnochromini, and a

28 new combination for Limnochromis abeelei and Limnochromis staneri is proposed:

29 Greenwoodochromis abeelei and Greenwoodochromis staneri. The revised tribe

30 Limnochromini, which consists of ten species belonging to seven genera, is

31 characterised by IOs representing types G and I, and the revised genus

32 Greenwoodochromis, which consists of four species, is characterised by IOs

33 representing type I.

34

35 Key words: infraorbitals; tribes; genus; classification; taxonomy. 


\section{INTRODUCTION}

In Lake Tanganyika, about 200 endemic cichlid species are currently considered valid, 40 and new species continue to be described (e.g., Takahashi \& Hori, 2006; Schelly et al., 41 2007; Verburg \& Bills, 2007; Takahashi, 2008; Burgess, 2012; Kullander et al., 2012).

42 These fishes are morphologically, ecologically and genetically diverse, and represent a 43 well-established model system for the study of adaptive radiation (e.g., Fryer \& Iles, 1972; Kornfield \& Smith, 2000; Turner et al., 2001; Kocher, 2004; Seehausen, 2006; Turner, 2007; Koblmüller et al., 2008; Salzburger, 2009; Sturmbauer et al., 2011; Takahashi \& Koblmüller, 2011; Gante \& Salzburger, 2012).

Poll (1986) first classified the Lake Tanganyika cichlid fishes into 12 tribes based on morphological features. Some molecular and morphological studies pointed out that this

50 classification was essentially reasonable but needed a few minor changes (Nishida,

51 1991; Kocher et al., 1995; Lippitsch, 1998; Salzburger et al., 2002). Subsequently,

52 Takahashi (2003a) constructed a cladogram of these fishes based on anatomical data and proposed a new classification that recognised 16 tribes. Takahashi’s (2003a) classification resolved some taxonomic problems with Poll's (1986) classification, but some molecular phylogenetic studies have highlighted the need for further minor changes (reviewed by Koblmüller et al., 2008). One of the contradictions between

57 Takahashi’s (2003a) classification and molecular phylogenetic studies raised a problem on the validity of the tribe Greenwoodochromini Takahashi, 2003 (Duftner et al., 2005). 
61 isolated from the tribe Limnochromini Poll, 1986 and Greenwoodochromini was

62 established for this genus [at the same time, Takahashi (2003a) also isolated the genus

63 Benthochromis Poll, 1986 from Limnochromini and established the tribe

64 Benthochromini Takahashi, 2003 for this genus, and moved Gnathochromis pfefferi

65 (Boulenger, 1898) from the Limnochromini to the Tropheini Poll, 1986, although

66 Gnathochromis permaxillaris (David, 1936), which is the type species of

67 Gnathochromis Poll, 1981, remained in Limnochromini]. However, the

68 Greenwoodochromini is nested within Takahashi’s (2003a) Limnochromini in a

69 molecular phylogeny resulting in a polyphyletic Limnochromini (Duftner et al., 2005;

70 and see Discussion).

Takahashi (2003a) used a morphological difference in the infraorbitals (IOs), which are bones surrounding the lower half of the eye, to distinguish the Greenwoodochromini from the Limnochromini. The IO series of the type species of Greenwoodochromis, Greenwoodochromis christyi (Trewavas, 1953), were identified as type A (according to the definitions of Takahashi, 2003b), which is the most common of the Lake Tanganyika cichlid flock; whereas the IOs of species of Limnochromini were identified as type G [Fig. 1(a); Takahashi, 2003a, b]. However, the number of specimens of G. christyi used by Takahashi (2003a, b) was small, and IOs from Greenwoodochromis bellcrossi (Poll, 80 1976), Limnochromis abeelei Poll, 1949, and Limnochromis staneri Poll, 1949 were not examined. Although few samples are available because of the difficulties in collecting

82 from deep-water habitats, the present study examined the IO series of six to 20

83 specimens from these four species. By combining the present anatomical data with

84 previously published molecular phylogenetic and morphological studies, the validity of 
85 Greenwoodochromini and the extent of Greenwoodochromis are discussed.

86

87

88

89

90

91

92

93

94

95

96

97

98

99

100

101

102

103 The number of bones in the IO series ranges from four to six in G. christyi, G. bellcrossi,

104 L. abeelei, and L. staneri (Table I). The anteriormost bone is larger than the others and

105 has a sensory canal that opens through five or six sensory pores. Four of the pores are

106

107

108

\section{MATERIALS AND METHODS}

Greenwoodochromis christyi, G. bellcrossi, L. abeelei, and L. staneri were collected off Mtondwe Island, Mpulungu, Zambia, with gill nets at 42-140 m depth between August 1995 and December 2007 and in October $2013(N=57)$. Fish were fixed in 10\% formalin. The standard length $\left(L_{\mathrm{S}}\right)$ of each fish was measured with digital callipers. The IOs on the left side of the head were observed. The IOs of some specimens were removed from the head and stained with Alizarin Red-S in 70\% ethyl alcohol, and sketches were made under a binocular microscope (Nikon SMZ 1000). A likelihood ratio test on a logistic regression was used to test any association between intra-specific variation in IOs and fish size. The term "anteriormost bone" is used instead of lacrimal.

\section{RESULTS} large; the widths of these pores are wider than the intervals between the pores [arrows in Fig. 2(a-c)]. The remaining small, tube-like bones have two to five (usually two) sensory pores each. 
110 Greenwoodochromis christyi has two major variations in IO configuration (Table I).

111 Thirteen out of the 20 individuals examined have six IOs with 6-2-2-2-2-2 sensory

112 pores [Fig. 2(b)], whereas five individuals have five IOs with 6-2-3-2-2 sensory pores

113 [Fig. 2(a)]. The third bone of the latter variation (6-2-3-2-2) is elongated and has three

114 sensory pores; two pores are located at the ends of the bone, and the other pore is

115 located anterior to the midpoint of the bone. The individuals that have five IOs with

116 6-2-3-2-2 sensory pores are significantly larger than the individuals that have six IOs

117 with 6-2-2-2-2-2 sensory pores (Fig. 3).

118

119 In G. bellcrossi and L. abeelei, the IO series varies greatly in numbers of bones and sensory pores, although smaller numbers of samples were examined compared to the

121 other species (Table I). The major variation accords with the IO configuration of the

122 large individuals of G. christyi (6-2-3-2-2). One individual of L. abeelei exhibits the

123 same configuration as the small individuals of G. christyi (6-2-2-2-2-2).

In L. staneri, the IO series varies somewhat in numbers of bones and sensory pores sensory pores [Fig. 2(c)]. The fourth bone is elongate and has a pore located at each end, and the other pore is located anterior to the midpoint of the bone. One individual exhibits the same condition as the small individuals of G. christyi (6-2-2-2-2-2). 
134 The IOs of G. christyi, G. bellcrossi, L. abeelei, and L. staneri are distinguishable from

135 those of the other Lake Tanganyika cichlids. In these species, four of the five or six

136 sensory pores on the anteriormost bone are large and the widths of these four pores are

137 wider than the intervals between the pores [Fig. 2(a-c)], whereas the widths of all the

138 sensory pores on the anteriormost bone are small and the widths of the pores are

139 narrower than the intervals between the pores in many other species (Takahashi, 2003b).

140 Species of Trematocara Boulenger, 1899 also have large pores on the anteriormost bone,

141 but all the pores (not only four of the pores) are large (Takahashi, 2002, 2003b).

143 Several variations were found in IO configuration of G. christyi, G. bellcrossi, L.

144 abeelei, and L. staneri (Table I). Taking into account the size and number of sensory

145 pores on the bones and distances between the pores, these variations may be a result of a

146 few fusion events between certain bones. For example, the anteriormost and second

147 bones of $L$. staneri [Fig. 2(c)] appear to be homologous with the anteriormost bone of $G$.

148 christyi [Fig. 2(a, b)], and the third and fourth bones of small individuals of G. christyi

149 [Fig. 2(b)] appear to be homologous with the third bone of the large individuals of $G$.

150 christyi [Fig. 2(a)] and the fourth bone of L. staneri [Fig. 2(c)]. Accordingly, assuming a

151 plesiomorphic IO configuration of 5-2-2-2-2-2-2, the most common condition of small

152 individuals of G. christyi (6-2-2-2-2-2) can be considered a result of fusion between the

153 first and second bones of the plesiomoprhic IO configuration [Fig. 2(b)]. The most

154 common condition of large individuals of G. christyi (6-2-3-2-2), which is also the most

155 common condition of G. bellcrossi and L. abeelei, can be considered a result of fusion

156 between the first and second bones and between the fourth and fifth bones of the 
157 plesiomorphic IO configuration [Fig. 2(a)]. Similarly, the most common condition of $L$.

158 staneri (5-2-2-3-2-2) can be considered a result of fusion between the fourth and fifth

159 bones of the plesiomorphic IO configuration [Fig. 2(c)]. Other minor variations can be

160 explained by an irregular increase in the number of sensory pores on a tube-like bone,

161 an increase or decrease of the number of tube-like bones, or unusual fusion event (see

162 Table I foot notes).

163

164 Takahashi (2003b) described IOs of Lake Tanganyika cichlids and classified them into

165 eight types: types A to H. Accordingly, the condition of the IOs unique to G. christyi, G.

166 bellcrossi, L. abeelei, and L. staneri is named 'type I', the ninth type. Type I can be

167 defined as IOs that have four large sensory pores on the anteriormost bone, and usually

168 consist of seven IOs with 5-2-2-2-2-2-2 sensory pores, of which the first and second IOs

169 and/or the fourth and fifth IOs are fused. Takahashi (2003b) considered the IOs of small

170 individuals of G. christyi (6-2-2-2-2-2) to be a variation of type A [Fig. 2(e) shows the

171 typical condition of type A, which has six bones with 5-2-2-2-2-2 sensory pores and the

172 sensory pores on the anteriormost bone are small]; however, the 6-2-2-2-2-2 condition is

173 regarded as type I in the present study.

174

175 In their phylogenetic analysis of Lake Tanganyika cichlids using mitochondrial DNA

176 (mtDNA) sequences, Duftner et al. (2005) inferred that nine of the ten species in

177 Takahashi’s (2003a) Greenwoodochromini and Limnochromini formed a monophyletic

178 group [Fig. 1(a)] (Tangachromis dhanisi (Poll, 1949) was not examined]. The

179 monophyly of this group is strongly supported by various statistical tests (e.g., 100\%

180 Bayesian posterior probability). A clade of Takahashi’s (2003a) Greenwoodochromini 
nested within the Limnochromini resulted in the Limnochromini and the genus

Limnochromis Regan 1920 [the type species is Limnochromis auritus (Boulenger, 1901)] being polyphyletic [Fig. 1(a)]. Although phylogenetic inference based on mtDNA can be heavily affected by incomplete lineage sorting and introgression (e.g., Rüber et al., 2001; Koblmüller et al., 2007a, b, 2010; Sturmbauer et al., 2010), the morphology of the IOs supports the monophyly of a clade including G. christyi, G. bellcrossi, L. abeelei and L. staneri [Fig. 1(b)], which is supported by $100 \%$ Bayesian posterior probability in the mtDNA tree (Duftner et al., 2005). To resolve the disagreements between systematic classification and phylogeny, it is proposed to synonymise Greenwoodochromini with Limnochromini and to make two new combinations: Greenwoodochromis abeelei and Greenwoodochromis staneri [Fig. 1(b)].

The IOs representing type G, which consists typically of three bones with the elongated second bone [Fig. 2(d); Takahashi, 2003b], and type I are unique to the revised Limnochromini. The species of Limnochromini inhabit bottoms at depths greater than $30 \mathrm{~m}$ (Poll, 1956). The large sensory pores on the anteriormost bone (type I) may possibly improve noise sensitivity in deep, dark environments, and fusion of bones (type G, type I) may possibly strengthen the structure.

200 In conclusion, the tribe Greenwoodochromini is synonymised with the tribe

201 Limnochromini. The revised Limnochromini consists of seven genera: Baileychromis,

202 Gnathochromis (excluding G. pfefferi, which is included in the tribe Tropheini),

203 Greenwoodochromis, Limnochromis, Reganochromis, Triglachromis and presumably

204 Tangachromis (although it's phylogenetic position has not been directly examined here 
205 of by Duftner et al., 2005). This Limnochromini is characterised by having the IOs

206 representing type G [Fig. 2(d)] and type I [Fig. 2(a-c)]. The genus Greenwoodochromis

207 is revised to include four species: G. abeelei (new combination), G. bellcrossi, G.

208 christyi (type species of this genus), and G. staneri (new combination). This genus is

209 characterised by having IOs representing type I.

210

211 Acknowledgements. I thank M. Hori for providing samples for the morphological

212 analyses and E. Nakajima for providing language help. This study was supported by

213 Grants-in-Aid for Young Scientists (No. 20770065) and Scientific Research (No.

214 23370043) of MEXT, Japan, and Global COE Program (A06) of Kyoto University.

215

216

217

\section{References}

218

Burgess, W. E. (2012). A new species of goby cichlid of the genus Eretmodus, E. marksmithi, (Pisces: Cichlidae) from the northern part of Lake Tanganyika. Tanganika Magazyn 12, 23-31.

222

Duftner, N., Koblmüller, S. \& Sturmbauer, C. (2005). Evolutionary relationships of the Limnochromini, a tribe of benthic deepwater cichlid fish endemic to Lake Tanganyika, East Africa. Journal of Molecular Evolution 60, 277-289. doi: 10.1007/s00239-004-0017-8

Fryer, G. \& Iles, T. D. (1972). The cichlid fishes of the great lakes of Africa. Neptune City, NJ: T.F.H. Publications.

228 Gante, H.F. \& Salzburger, W. (2012). Evolution: Cichlid models on the runaway to 
speciation. Current Biology 22, R956-958. doi: 10.1016/j.cub.2012.09.045

Koblmüller, S., Duftner, N., Sefc, K. M., Aibara, M., Stipacek, M., Blanc, M., Egger, B.

231

232

233

234

235

236

237

238

239

240

241

242

\& Sturmbauer, C. (2007a). Reticulate phylogeny of gastropod-shell-breeding cichlids from Lake Tanganyika - the result of repeated introgressive hybridization. BMC Evolutionary Biology 7, 7. doi: 10.1186/1471-2148-7-7

Koblmüller, S., Egger, B., Sefc, K. M. \& Sturmbauer, C. (2007b). Evolutionary history of Lake Tanganyika’s scale-eating cichlid fishes. Molecular Phylogenetics and Evolution 44, 1295-1305. doi: 10.1016/j.ympev.2007.02.010

Koblmüller, S., Sefc, K. M. \& Sturmbauer, C. (2008). The Lake Tanganyika cichlid species assemblage: recent advances in molecular phylogenetics. Hydrobiologia 615, 5-20. doi: 10.1007/s10750-008-9552-4

Koblmüller, S., Egger, B., Sturmbauer, C. \& Sefc, K. M. (2010). Rapid radiation, ancient incomplete lineage sorting and ancient hybridization in the endemic Lake Tanganyika cichlid tribe Tropheini. Molecular Phylogenetics and Evolution 55, 318-334. doi: 10.1016/j.ympev.2009.09.032

Kocher, T. D. (2004). Adaptive evolution and explosive speciation: the cichlid fish model. Nature Reviews Genetics 5, 288-298. doi: 10.1038/nrg1316

Kocher, T. D., Conroy, J. A., McKaye, K. R., Stauffer, J. R. \& Lockwood, S. F. (1995). Evolution of NADH dehydrogenase subunit 2 in east African cichlid fish. Molecular Phylogenetics and Evolution 4, 420-432.

Kornfield, I. \& Smith, P.F. (2000). African cichlid fishes: model systems for evolutionary biology. Annual Review of Ecology and Systematics 31, 163-196.

Kullander, S. O., Karlsson, M. \& Karlsson, M. (2012). Lepidiolamprologus kamambae, a new species of cichlid fish (Teleostei: Cichlidae) from Lake Tanganyika. Zootaxa 
3492, 30-48.

254 Lippitsch, E. (1998). Phylogenetic study of cichlid fishes in Lake Tanganyika: a

255 lepidological approach. Journal of Fish Biology 53, 752-766.

256 Nishida, M. (1991). Lake Tanganyika as an evolutionary reservoir of old Lineages of 257 East African cichlid fishes: inferences from allozyme data. Experientia 47, 974258979.

Poll, M. (1956). Poissons Cichlidae. Résultats Scientifiques Exploration Hydrobiologique du Lac Tanganika (1946-1947). Institut Royal des Sciences Naturelles de Belgique 3(5B), 1-619.

Poll, M. (1986). Classification des Cichlidae du lac Tanganika. Tribus, genres et espèces. Académie Royale de Belgique, Mémoires de la Classe des Sciences 45, 1-163.

Rüber, L., Meyer, A., Sturmbauer, C. \& Verheyen, E. (2001). Population structure in two sympatric species of the Lake Tanganyika cichlid tribe Eretmodini: evidence for introgression. Molecular Ecology 10, 1207-1225.

Salzburger, W. (2009). The interaction of sexually and naturally selected traits in the adaptive radiations of cichlid fishes. Molecular Ecology 18, 169-185. doi: 10.1111/j.1365-294X.2008.03981.X

Salzburger, W., Meyer, A., Baric, S., Verheyen, E. \& Sturmbauer, C. (2002). Phylogeny of the Lake Tanganyika cichlid species flock and its relationship to the central and

Schelly, R., Takahashi, T., Bills, R. \& Hori, M. (2007). The first case of aggressive mimicry among lamprologines in a new species of Lepidiolamprologus (Perciformes: Cichlidae) from Lake Tanganyika. Zootaxa 1638, 39-49.

276 Seehausen, O. (2006). African cichlid fish: a model system in adaptive radiation 
277

278

279

280

281

282

283

284

285

286

287

288

289

290

291

292

293

294

295

296

297

298

299

300

research. Proceedings of the Royal Society of London B 273, 1987-1998. doi: 10.1098/rspb.2006.3539

Sturmbauer, C., Salzburger, W., Duftner, N., Schelly, R. \& Koblmüller, S. (2010). Evolutionary history of the Lake Tanganyika cichlid tribe Lamprologini (Teleostei: Perciformes) derived from mitochondrial and nuclear DNA data. Molecular Phylogenetics and Evolution 57, 266-284. doi: :10.1016/j.ympev.2010.06.018

Sturmbauer, C., Husemann, M. \& Danley, P. D. (2011). Explosive speciation and adaptive radiation of East African cichlid fishes. Biodiversity Hotspots 2011, 333362. doi: 10.1007/978-3-642-20992-5_18

Takahashi, T. (2002). Systematics of the tribe Trematocarini (Perciformes: Cichlidae) from Lake Tanganyika, Africa. Ichthyological Research 49, 253-259.

Takahashi, T. (2003a). Systematics of Tanganyikan cichlid fishes (Teleostei: Perciformes). Ichthyological Research 50, 367-382. doi: $10.1007 / \mathrm{s} 10228-003-0181-7$

Takahashi, T. (2003b). Comparative osteology of the infraorbitals in cichlid fishes (Teleostei: Perciformes) from Lake Tanganyika. Species Diversity 8, 1-26.

Takahashi, T. (2008). Description of a new cichlid fish species of the genus Benthochromis (Perciformes: Cichlidae) from Lake Tanganyika. Journal of Fish Biology 72, 603-613. doi: 10.1111/j.1095-8649.2007.01727.x

Takahashi, T. \& Hori, M. (2006). Description of a new Lake Tanganyikan cichlid fish of the genus Cyprichromis (Perciformes: Cichlidae) with a note on sexual dimorphism. Journal of Fish Biology 68, 174-192. doi: 10.1111/j.1095-8649.2006.01055.x

Takahashi, T. \& Koblmüller, S. (2011). The adaptive radiation of cichlid fish in Lake 
301 Tanganyika: a morphological perspective. International Journal of Evolutionary

302 Biology 2011, article ID 620754. doi: 10.4061/2011/620754

303 Turner, G. F. (2007). Adaptive radiation of cichlid fish. Current Biology 17, R827$304 \quad$ R831.

305 Turner, G. F., Seehausen, O., Knight, M. E., Allender, C. J. \& Robinson, R. L. (2001).

306 How many species of cichlid fishes are there in African lakes? Molecular Ecology $307 \quad \mathbf{1 0}, 793-806$.

308 Verburg, P. \& Bills, R. (2007). Two new sympatric species of Neolamprologus

309 (Teleostei: Cichlidae) from Lake Tanganyika, East Africa. Zootaxa 1612, 25-44. 
1 Figure legends

2

3 FIG. 1. Schematic molecular phylogeny of nine of the ten species composing

4 Takahashi’s (2003a) Limnochromini and Greenwoodochromini presented by Duftner et

5 al. (2005). Phylogenetic position of Tangachromis dhanisi remains unknown. Letters on

6 the right of the scientific names indicate types of infraorbitals. Boxes indicate tribal

7 classification. (a) The infraorbital types (Takahashi, 2003b), generic classification (Poll,

8 1986), and tribal classification (Takahashi, 2003a) of previous studies. (b) The

9 infraorbital types, generic classification, and tribal classification according to the

10 present study.

12 FIG. 2. Infraorbital (IO) series on the left side of the head representing (a-c) type I, (d)

13 type $\mathrm{G}$ and (e) type A. The bones are numbered from anterior to posterior (figures above

14 the bones). Arrows indicate four large sensory pores on the anteriormost bone.

15 Characters connected by pluses under the bones indicate suggested fusion patterns of

16 IOs (see text for details). (a, b) Greenwoodochromis christyi (110.6 mm Ls and $70.3 \mathrm{~mm}$

$17 \quad L_{\mathrm{s}}$, respectively), (c) Limnochromis staneri (130.1 $\mathrm{mm} \mathrm{Ls),} \mathrm{(d)} \mathrm{Limnochromis} \mathrm{auritus}$

18 (114.4 mm Ls), and (e) Simochromis diagramma (Günther 1894) (130.0 mm Ls). Bars

19 indicate $5 \mathrm{~mm}$.

20

21 FIG. 3. Relationship between body size and configuration of IOs (six bones with

23 Greenwoodochromis christyi. 
(a) Previous studies

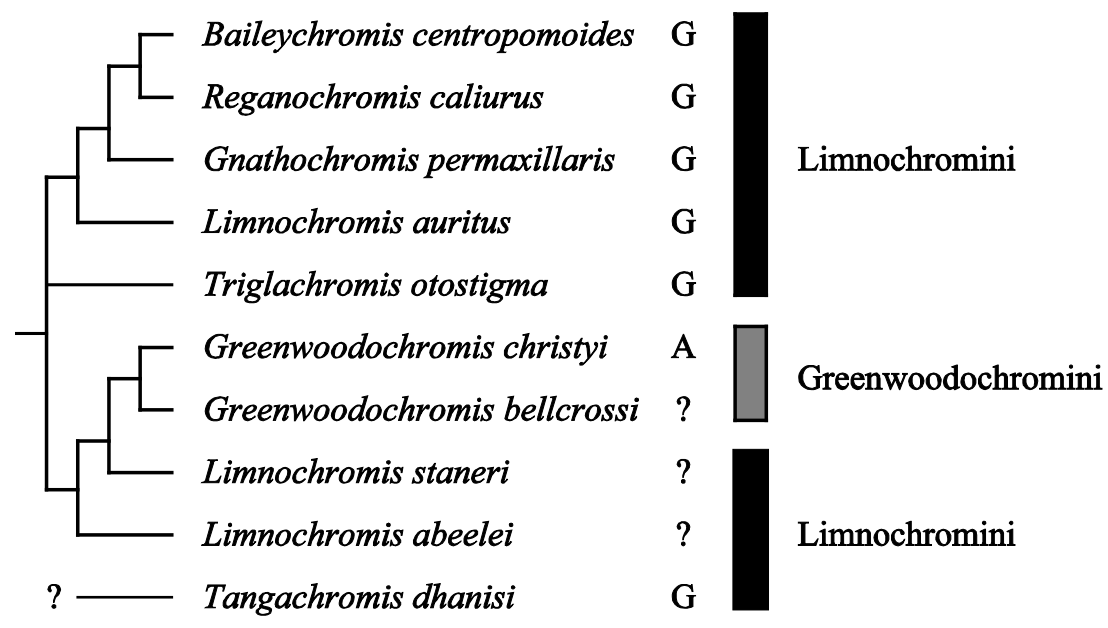

(b) Present study

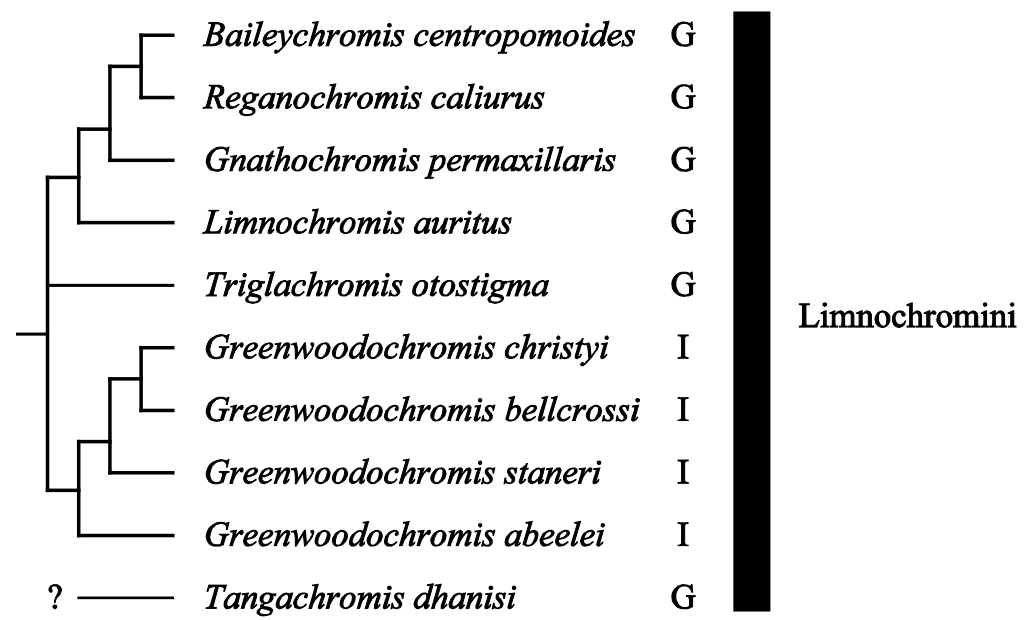



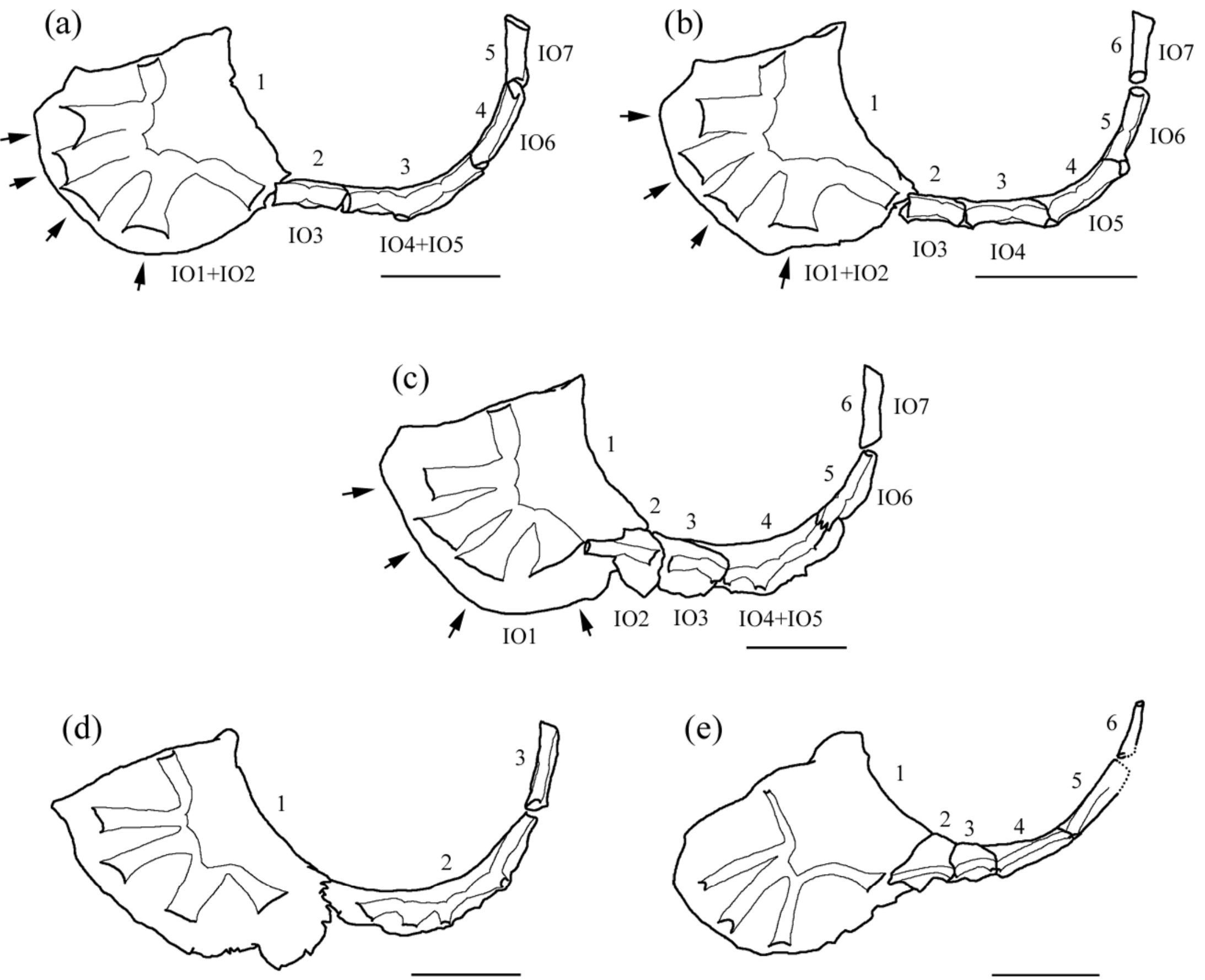

Fig. 2 


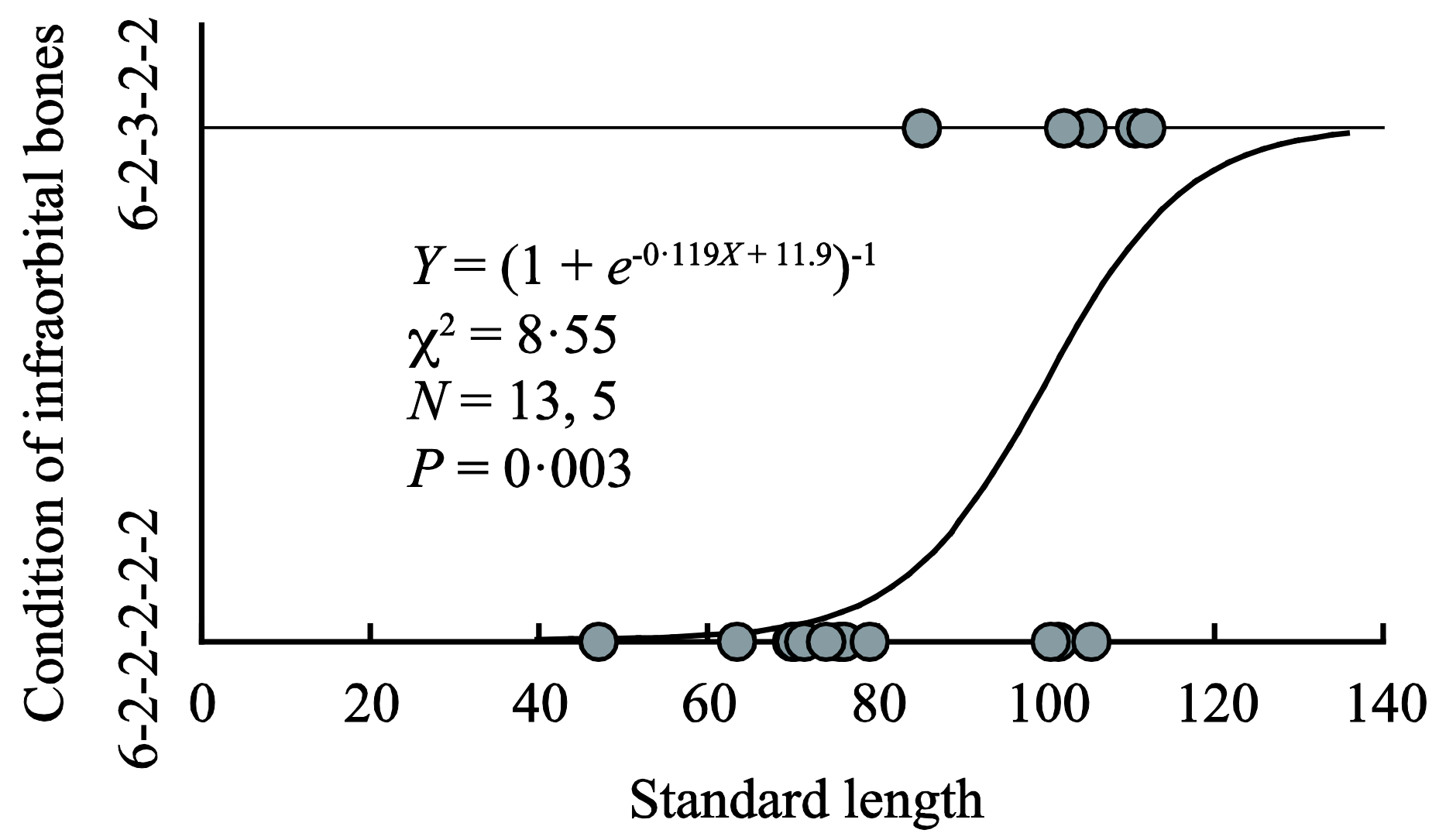

Fig. 3 